Gdańsk 2019, Nr. 41

https://doi.org/10.26881/sgg.2019.41.17

Katarzyna Lukas

Universität Gdańsk

https://orcid.org/0000-0003-0632-8966

\title{
Die Hanse als instrumentalisierter Erinnerungsort in touristischen Flugschriften aus der Freien Stadt Danzig (1920-1939)
}

\begin{abstract}
Gegenstand des Beitrags sind deutschsprachige touristische Flugschriften aus der Zeit der Freien Stadt Danzig (1920-1939), die sich an potentielle Besucher aus dem Deutschen Reich wenden. Die analysierten Flugschriften wurden für Werbe- und Propagandazwecke eingesetzt. Sie bewerben die Freie Stadt Danzig als Urlaubsziel, versuchen aber nebenbei, die Rezipienten von dem genuin deutschen Charakter Danzigs als ehemalige Hansestadt zu überzeugen. Um die kollektive Identität der deutschen Adressaten anzusprechen, werden in die Texte Referenzen auf die Hanse als Erinnerungsort und stereotype „Verkörperung des Deutschtums“ eingebaut. Das Stereotyp der Hanse wird auf zwei Ebenen aktiviert: auf der sprachlichen (durch klischeehafte Phrasen und wertende Attribute, die sich explizit auf die glorreiche hansische Vergangenheit von Danzig beziehen) und auf der visuellen (durch Bilder von Danziger Bauwerken, die im Hanse-Stil erbaut wurden).
\end{abstract}

Schlüsselwörter: Flugschriften, Freie Stadt Danzig, die Hanse, Erinnerungsort, Manipulation

The Hanseatic League as a 'memory site' exploited in tourist leaflets from the Free City of Danzig (1920-1939). - The paper deals with a selection of tourist leaflets published in the Free City of Danzig in the interwar period (1920-1939), written in German and addressed to German visitors from the German Reich. The leaflets subject to the analysis were produced mainly for propaganda reasons. Promoting the Free City as a tourist destination, the leaflets aim at convincing the addressees of the genuine German identity of Danzig as a former Hanseatic city. To intensify the national sentiment of the target recipients, the texts in the leaflets employ the stereotype and 'memory site' (Erinnerungsort) of the Hanseatic League as the embodiment of the German spirit. The leaflets exploit the image of the League on a visual level (by using pictures of selected Hanseatic-style buildings in Danzig) and by linguistic means (allusions and explicit references to the glorious Hanseatic past of Danzig).

Keywords: ephemera, Free City of Danzig, Hanseatic League, memory site, manipulation

\section{Touristische Ephemera aus der Freien Stadt Danzig: Gattungszugehörigkeit, Perspektiven ihrer Erforschung}

Gegenstand des vorliegenden Beitrags ist eine Gruppe von ephemeren Drucken, die den Sammlungen der Bibliothek der Polnischen Akademie der Wissenschaften in Gdańsk, 
Abteilung für Ephemera, ${ }^{1}$ entstammen. Es handelt sich dabei um auf Deutsch verfasste Broschüren und Faltblätter aus der Zeit der Freien Stadt Danzig (1920-1939), die das damalige Danzig, Zoppot und deren Umgebung als Reiseziel für deutschsprachige Touristen bewerben (vgl. Abb. 1-2). Die einzelnen Drucke unterscheiden sich voneinander im Hinblick auf die Gestalt, das Format und den Umfang; sie umfassen von einigen wenigen bis zu rund zwanzig Seiten. Somit lassen sie sich in das Kontinuum von ephemeren Drucken einordnen, das nach Schottenloher (1922: 16-17) von einem Flugblatt über eine Flugschrift bis hin zu einer Broschüre reicht. ${ }^{2}$ Die zu besprechenden Ephemera stellen keine Flugblätter sensu stricto (Einblattdrucke) dar, denn sie bestehen jeweils aus mehr als nur einem (ein- oder beiderseitig bedruckten) Blatt. Deswegen verwende ich im Folgenden wechselweise die Bezeichnungen „Flugschrift“, „Broschüre“ und gegebenenfalls auch „Faltblatt" wegen der kunstvoll zusammengelegten Form mancher Drucke.

Die Autoren der Ephemera aus der Freien Stadt Danzig bleiben zumeist anonym, lediglich als Herausgeber wird darin oft die „Danziger Verkehrszentrale“ angegeben, mit einer Adresse in Danzig (Stadtgraben 5) und in Berlin (Unter den Linden 16 bzw. 47). Dabei handelt es sich um eine 1907 gegründete öffentliche Stelle, die die Aufgaben einer Tourist-Information übernahm und für die Bewerbung von Danzig als Urlaubsziel sowie für die Förderung des Fremdenverkehrs in der Region zuständig war. ${ }^{3} \mathrm{Zu}$ den Rezipienten der Flugschriften liegen keine Angaben vor. Ebenso schwach belegt und wohl nicht mehr nachvollziehbar ist es, ob die Wirkung der Danziger touristischen Ephemera lokal begrenzt war oder doch überregional über das Gebiet der Freien Stadt Danzig hinausreichte. Es liegt zwar die Vermutung nahe, dass sich die Flugschriften in erster Linie an Touristen richteten, die an ihrem Urlaubsziel

1 Der offizielle Name dieser traditionsreichen Einrichtung lautet auf Polnisch: PAN Biblioteka Gdańska. An dieser Stelle möchte ich mich bei Aneta Kwiatkowska, Mitarbeiterin der PAN Bibliothek, Abteilung für Ephemera, für die freundliche Bereitstellung des hier besprochenen Textmaterials sowie für ihre wichtigen bibliographischen Hinweise bedanken. Mein weiterer Dank gebührt Dr. Jan Daniluk für seine aufmerksame Lektüre dieses Aufsatzes, seine hilfreichen Kommentare und Korrekturen aus der Perspektive eines Historikers. Der PAN Biblioteka Gdańska danke ich für die freundliche Genehmigung, die abgebildeten Flugschriften aus ihren Sammlungen in diesem Beitrag verwenden zu dürfen.

2 Nach Schottenloher sind Übergänge zwischen diesen drei Formen der ephemeren Drucke fließend. Das Hauptmerkmal eines Flugblatts sei „schlagende Kürze“, es baue auf „gedrängter, verständlicher, packender, wuchtiger [...] Ansprache an den Leser" auf (Sснотt enloher 1922: 17). Die Flugschrift sei ein erweitertes Flugblatt, das „an die Geduld und Zeit des Lesers größere Ansprüche [stellt]“ (ebd.), die Broschüre wiederum stelle eine erweiterte Flugschrift dar. Ausschlaggebend für die Gattung sei nicht die genau festgelegte Seitenzahl, sondern vielmehr die Aktualität und angestrebte Wirkung auf den Leser (vgl. auch die Lemmata „Flugschrift“, „Flugblatt“, „Broschüre“ im Lexikon des gesamten Buchwesens). In MLMM (2002: 40) werden Einblattdrucke, Flugblätter und broschürenartige Flugschriften dem Buch gegenübergestellt, allerdings ohne dass ihr Umfang genau bestimmt wird. Anders verhält es sich in der polnischen Buchwissenschaft, die die weniger umfangreichen Druckerzeugnisse im Hinblick auf die Anzahl der Blätter einteilt. So umfasst eine ,Flugschrift' (ulotka) bis zu vier Seiten, eine Broschüre (broszura) dagegen - bis zu 48 Seiten (vgl. EWoK, Spalte 339-340, 560-561; vgl. auch Firlej-Buzon (2002: 28)). Sämtliche hier zu besprechenden Drucke fallen somit unter die Kategorie einer ,Flugschrift' und einer ,Broschüre‘ im Sinne der polnischen bücherkundlichen Tradition. Zu den Differenzen in der buchwissenschaftlichen Terminologie in verschiedenen Sprachen vgl. Migoń (2006: 11-17).

3 Persönliche Mitteilung von Jan Daniluk (10.10.2018). 


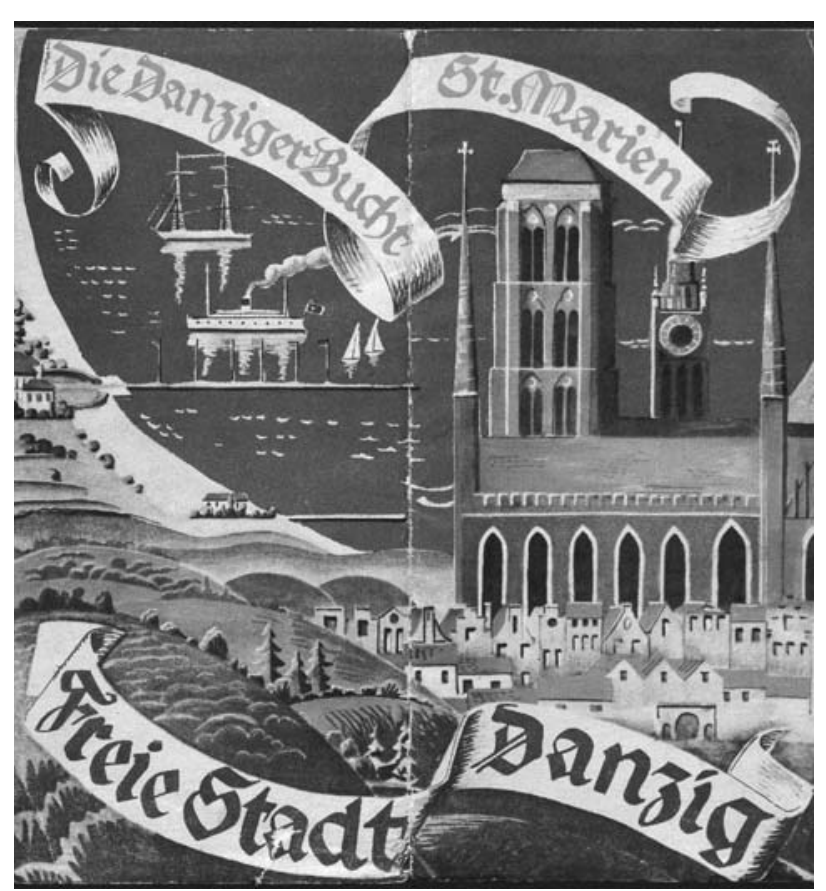

Abb. 1. Flugschrift „Freie Stadt Danzig“, Rück- und Vorderseite des Umschlags (5107/17)

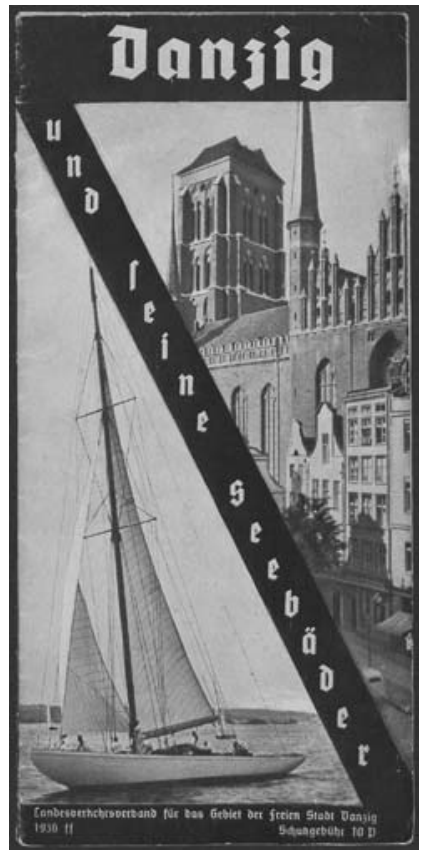

Abb. 2. Faltblatt „Danzig und seine Seebäder", Vorderseite des Umschlags (5093/17)

bereits angekommen waren. ${ }^{4}$ Dass die Danziger Verkehrszentrale auch in Berlin tätig war, spricht jedoch dafür, dass ihr Werbematerial im Deutschen Reich ebenfalls verbreitet wurde. ${ }^{5}$

Die Drucke präsentieren das Kultur- und Freizeitangebot sowie die Erholungsmöglichkeiten in Danzig und Zoppot - einem Ostseebad, das sich bei den Deutschen in der Zwischenkriegszeit großer Popularität erfreute. ${ }^{6}$ Einige der Flugschriften besitzen ausschließlich Informationscharakter, sie geben die Preise für verschiedene Dienstleistungen, Übernachtungen, Eintrittskarten, Kosten für Verpflegung und Transport, Adressen von Geschäften etc. an. ${ }^{7}$ Viel häufiger aber spielt die Information eine untergeordnete Rolle. Die Texte, die sich

4 Für potentielle Touristen in Deutschland, die ihren Besuch in der Freien Stadt Danzig erst planten, waren wohl eher Reiseführer in Buchform bestimmt. Heute verhält es sich ähnlich: Flug- und Faltblätter über die jeweilige Stadt und ihre Sehenswürdigkeiten sind nur vor Ort verfügbar, sie liegen zur Mitnahme in Hotels, Museen, Kirchen, Tourist-Information u. ä. aus.

5 Wie Loew (2011:212) bemerkt, war es „der freistädtischen Politik [...] wichtig, dass Danzig im großen deutschen Vaterland wahrgenommen wurde.“ Im Vergleich zu großen kulturellen oder Sportveranstaltungen, mit denen Danzig über seine Grenzen hinaus für sich warb (vgl. ebd.), wäre der Versand von touristischen Flugschriften nach Deutschland ein billiges Werbemittel gewesen. Zudem dürften die hier behandelten Ephemera auf privaten Wegen ins Deutsche Reich gelangt sein, indem sie von heimkehrenden Touristen mitgebracht wurden.

6 Aus der Statistik von AnDRZEJEws Ki (1998: 172) geht hervor, dass sich die Anzahl deutscher Touristen in Zoppot im Zeitraum von 1920 bis 1934 mehr als verdreifachte und 1934 bereits deutlich über 12.000 lag. Aus Deutschland stammte auch die Mehrheit der Zoppoter Kurgäste.

Zum Beispiel das Faltblatt Was kostet der Aufenthalt in Danzig (4791/16). 
an deutschsprachige Leser richten, haben zur Aufgabe, das Bild der Freien Stadt Danzig und von ganz Pommerellen als eines integralen Bestandteils der deutschen Kulturgemeinschaft zu vermitteln. Das Ziel jener im Fremdenverkehr eingesetzten Danziger Flugschriften ist offene Persuasion, manchmal auch versteckte Manipulation. ${ }^{8}$ Diese beiden kommunikativen Intentionen werden verwirklicht, indem die Autoren der Broschüren nicht nur bestimmte rhetorische Mittel verwenden, sondern auch das Verbale durch geschickt ausgewähltes Bildmaterial wie Fotos und Landkarten unterstützen. Auf die Unentbehrlichkeit von visuellen Elementen, die die Wirksamkeit eines Flugblatts bzw. einer Flugschrift erhöhen, hat bereits SCHOTTENLOHER (1922: 17) hingewiesen: „Gerne nimmt das schlagwortartige, packende Flugblatt das Bild, die Zeichnung, zur Verstärkung der erstrebten Wirkung zu Hilfe, und in der Tat verfehlt der geschickt gestaltete Bilderbogen selten seinen Zweck.“

Gattungsmäßig erfüllen die touristischen Flugschriften aus der Freien Stadt Danzig alle Kriterien, die für das ephemere Schrifttum insgesamt, unabhängig von seiner Thematik, ausschlaggebend sind: „Das Wesen dieser unbuchmäßigen Mitteilungsformen ist möglichste Kürze und Gedrängtheit, rasche Darbietung und Beweglichkeit, engste Verbindung mit den Angelegenheiten des öffentlichen Lebens und den Forderungen des Tages“" (SCHOtTenloher 1922: 16). Ein weiteres grundsätzliches Merkmal von Flugschriften ist ihre ausgeprägte Appellfunktion: „Einstellung auf ein bestimmtes Ziel, Überredung und Einwirkung auf den Willen der Leser" (ebd.: 19). Wie Migoń (2006: 14) betont, sind Flugschriften an das Zeitgeschehen gebunden, das sie in der Regel subjektiv darstellen. Da sie häufig in den Dienst der Propaganda gestellt werden, haben sie als historische Quellen nur bedingten Wert: „Die Kundgebungen des Tagesschrifttums sind immer die Meinungen über die Dinge, nie die Dinge selbst" (Schottenloher 1922: 19). Ephemere Drucke repräsentieren somit die Wirklichkeit, konstruieren sie aber zugleich für bestimmte Leser und mit einem bestimmten Zweck.

Trotz ihres geringen Umfangs weisen Flugschriften, die im Fremdenverkehr eingesetzt werden, viele Gemeinsamkeiten mit Reiseführern in Buchform auf. Als Forschungsgegenstand wird die Textsorte Reiseführer eher in den Randgebieten der Philologie verortet. Beachtliches Interesse hingegen hat diese Gattung bisher in der Geographie und den sozialwissenschaftlichen Disziplinen gefunden, etwa in der Tourismusforschung und der Volkskunde, während sich die Reiseführer-Forschung in der interkulturellen Germanistik noch in der Konstitutionsphase befindet (vgl. WANG 2003: 582). Gegenwärtige Reiseführer, Bildbände, Broschüren und Flugschriften, die in Übersetzungen bzw. mehrsprachigen Versionen für ausländische Touristen erscheinen, werden oft auf den gemeinsamen Nenner der „Werbetexte im Fremdenverkeh" "gebracht und in translatorischer bzw. translationswissenschaftlicher Reflexion thematisiert (vgl. Mocarz 2011, SMYkaEa 2015, Lukas 2011, ResCH 2006: 74-90). Diese Perspektive ist durchaus begründet, denn die Textsorte „Werbetext

8 Ich greife hier die Thesen von Ewa Gruszczyńska auf, die zwei grundsätzliche, in ephemeren Drucken realisierte Sprachfunktionen unterscheidet: Information und Überredung. Die letztere Funktion kann die Gestalt von Persuasion (die auf das Bewusstsein des Rezipienten einwirkt) oder Manipulation (die den Rezipienten unbewusst beeinflusst) annehmen (vgl. GruszczyŃsKa 2012: 59). Gruszczyńska passt dabei die von GrZEGORCZYKOWA (1991) vorgeschlagene Typologie der Aussagefunktionen ihrer Forschung zu Ephemera an. 
im Fremdenverkehr" kommt im beruflichen Alltag eines Übersetzers besonders häufig vor. Daher nimmt es nicht wunder, dass gerade Translationstheoretiker touristische Flugschriften in einem breiten Spektrum an pragmatischen Texten als möglichen Übersetzungsvorlagen zutreffend verortet haben. Entscheidend für die Festlegung der Gattungsspezifik touristischer Broschüren war die Erkenntnis, dass Texte dieser Art zugleich eine informative, appellative und ästhetische Funktion erfüllen. Mitteilung, Persuasion und poetische Mittel kommen in touristischen Werbetexten in unterschiedlichen Mischungsverhältnissen vor, wobei die appellative Funktion den beiden anderen übergeordnet ist. Berücksichtigt man die in der Translationswissenschaft wohlbekannte übersetzungsorientierte Texttypologie von Katharina ReIss (2000), sollte auch beachtet werden, dass touristische Flugblätter wegen der aus ihnen nicht wegzudenkenden Illustrationen eine multimediale Textvariante (ebd.: 87) darstellen - in diesem Fall: ein Text-Bild-Gefüge.

Unter welchen Gesichtspunkten lassen sich ephemere Drucke untersuchen, die vor beinahe hundert Jahren in Danzig im Fremdenverkehr eingesetzt wurden? Grundsätzlich sind hier zwei Perspektiven möglich: eine philologische und eine kulturwissenschaftlich-historische. In der Praxis sind sie schwer auseinanderzuhalten, zumal eine tiefgehende Analyse eines gegebenen Druckes beide Perspektiven berücksichtigen soll. Geht man vom philologischen Standpunkt aus, werden an den Text etwa folgende Fragen herangetragen: Mit welchen rhetorischen Mitteln werden in den Danziger Flugschriften die informative, die appellative und die ästhetische Funktion von Werbetexten realisiert? Welche sprachlichen Stereotype, darunter auch metaphorischen Bilder literarischer Provenienz, werden darin getätigt und wie bilden sie gemeinsam ein Konstrukt höherer Ordnung, d. h. den Diskurs? Die Ephemera aus der Freien Stadt Danzig, in denen graphische Elemente in der Regel über dem verbalen Text dominieren, sind auch potentieller Forschungsgegenstand der Bildlinguistik - eines sprachwissenschaftlichen Teilgebiets, das sich seit einiger Zeit intensiv entwickelt.

Die kulturwissenschaftlich-historische Herangehensweise erlaubt es wiederum herauszufinden, wie sich Epoche machende geschichtliche Ereignisse in den ephemeren Drucken widerspiegeln, wie die Erinnerung an sie in das kollektive Bewusstsein eingeht und dort funktioniert. Im Fall der Danziger Flugschriften ist die Gründung der Freien Stadt Danzig (1920) sicherlich ein solches Ereignis. Die deutsche Bevölkerung sowohl in Danzig als auch im Reich empfand die Entstehung dieses politischen Gebildes als historisches Unrecht, was sich auch in der Sprache der touristischen Flugschriften niederschlug. Darüber hinaus speichern Ephemera die Erinnerung an das Alltagsleben ihrer Adressaten - die „Mikrogeschichte“ bzw. Alltagsgeschichte. Der Inhalt der Danziger Broschüren lässt auf den Lebensstil, die Gewohnheiten und Interessen der deutschsprachigen Kurgäste schließen, die das reichhaltige Angebot des Ostseebades Zoppot in Anspruch nahmen.

Flugschriften für deutsche Touristen aus dem Reich sind ein ausgezeichnetes Material für Forschungen zur Inter- und Transkulturalität, Kulturkomparatistik und Xenologie, die den konstruierten Gegensatz „Fremdes vs. Eigenes“ und dessen Rolle bei der kollektiven Identitätsbildung in den Blick nehmen. Die Danziger Ephemera stellen den deutschen Charakter der Stadt heraus, stilisieren deren Bild zum Symbol des Eigenen, sprich: des Deutschen. Die Präsenz der polnischen Institutionen und Verwaltungsorgane, der polnischen Sprache und 
Kultur wird entweder verschwiegen oder als unerwünschter Übergangszustand dargestellt, dem die Erinnerung an die jahrhundertealte deutsche Tradition vor Ort entgegenzuhalten ist.

In der kulturwissenschaftlich-historischen Erforschung von Ephemera und ihrer Mitwirkung bei der Konstruktion von Gruppenidentitäten ist die Kategorie des kollektiven Gedächtnisses nicht wegzudenken. Der Begriff umfasst sowohl das kulturelle Gedächtnis im Sinne von Jan AssmanN (1988), das überwiegend aus kanonischen Kulturtexten besteht, als auch das kulturelle „Gegengedächtnis“(A. Assmann 2009: 385), das sich in trivialen, kurzlebigen Gebrauchstexten ohne Anspruch auf dauernden ästhetischen Wert niederschlägt. Dabei können sowohl kanonische Texte als auch „textueller Abfall“ gleichermaßen zu Trägern von Erinnerungsorten im Sinne von Nora (1998) werden. Bei den lieux de mémoire handelt es sich um materielle wie immaterielle Gegebenheiten, „reale wie mythische Gestalten und Ereignisse, Gebäude und Denkmäler, Institutionen und Begriffe, Bücher und Kunstwerke“ (François / Schulze 2009: 17-18), an denen sich die gemeinsame Vergangenheit einer Gemeinschaft vergegenwärtigt und deren kollektive Identität stiftet. Erinnerungsorte sind etwas anderes als objektive historische Fakten; vielmehr sind es wandelbare und verhandelbare Phänomene, die sich im Spannungsfeld zwischen Wirklichem und Imaginärem bewegen und daher anfällig für verschiedene Interpretationen, Instrumentalisierung, Vereinnahmung und Manipulation sind (vgl. Gó RNY et al. 2012: 19). Dies betrifft insbesondere solche lieux de mémoire, die den kollektiven Gedächtnissen zweier oder mehrerer Kulturgemeinschaften angehören, wie es mit den Polen und Deutschen in der Freien Stadt Danzig der Fall ist.

Ein Erinnerungsort teilt bestimmte Eigenschaften mit einem ephemeren Druck: Er ist ein genauso ephemeres Phänomen, das eine Zeitlang im Diskurs dominieren kann; seine identitätsbildende Kraft kann aber mit der Zeit nachlassen, und seine Präsenz im kollektiven Gedächtnis geht in den Zustand von Latenz über. Es kommt vor, dass solch ein „schlummernder" Gedächtnisort unter dem Einfluss der Tagespolitik, aber auch durch einen langfristigen wirtschaftlichen, gesellschaftlichen und kulturellen Wandel wieder „aufwacht“ und für neue, aktuelle Bedeutungszuschreibungen offen steht. Ein derart ephemerer, zugleich aber besonders zählebiger Erinnerungsort des deutschen und polnischen kollektiven Gedächtnisses ist die Hanse. 9 In den touristischen Flugschriften der Freien Stadt Danzig - eines anderen hier relevanten deutsch-polnischen Erinnerungsortes (vgl. LoEw 2015: 123) - wird sie für Werbe- und Propagandazwecke eingesetzt. Im Folgenden gehe ich darauf ein, wie die Hanse als deutscher und polnischer Erinnerungsort in den hier interessierenden Texten konstruiert wird.

\section{Die Hanse: Erinnerungsort und Stereotyp}

Die Hanse war eine Vereinigung zunächst von niederdeutschen Kaufleuten (Kaufmannshanse), dann von ganzen Städten (Städtehanse) im Ost- und Nordseeraum, die zwischen Mitte des 12. Jahrhunderts und Mitte des 17.Jahrhunderts bestand. Den Fernkaufleuten, die der Hanse

9 Die Hanse ist mit Sicherheit ein deutscher und ein polnischer Gedächtnisort gleichermaßen. Davon zeugt ihre Berücksichtigung sowohl in der dreibändigen Monographie Deutsche Erinnerungsorte als auch in der mehrbändigen Arbeit Deutsch-Polnische Erinnerungsorte, in denen ihr jeweils ein eigenes Kapitel gewidmet ist. 
angehörten, sollte der Bund die Sicherheit der Seeüberfahrt, die Vormachtstellung im Ostseehandel und die Durchsetzung der gemeinsamen wirtschaftlichen Interessen garantieren.

Schon lange vor dem postmodernen memory boom stellten SCHILDHAUER / FRITZE / STARK (1972: 8) den scheinbar seltsamen Widerspruch heraus, „daß einerseits die Erinnerung an die Existenz dieses Städtebundes so lange lebendig, andererseits aber nur so blaß und unbestimmt geblieben ist." Aus der Sicht der heutigen kulturwissenschaftlichen Gedächtnisforschung ist dieses Paradoxon dahingehend zu verstehen, dass die Hanse ihrem Wesen nach die prototypischen Merkmale eines Erinnerungsortes geradezu verkörpert: dessen ephemere Natur, zugleich aber paradoxerweise die „lange Dauer“, d.h. das latente Überdauern in der Perspektive der longue durée im Sinne von Braudel (1977), des Weiteren die Offenheit eines Erinnerungsortes für divergente historische Deutungen, seinen transkulturellen und übernationalen Charakter (vgl. HACKMANN 2015: 85). Die Hanse war weder rechtlich noch institutionell begründet, sie war kein Staat, sondern eine lose Vereinigung, ein Gebilde mit verschwommenen Konturen. Zwar lassen sich bestimmte historische Eckdaten nennen: 1356 - der erste Hansetag und die Gründung der Städtehanse; der Untergang der Hanse nach dem Dreißigjährigen Krieg, 1669 - der letzte Hansetag in Lübeck und die offizielle Auflösung des Bundes (vgl. die Zeittafel in Dollinger 1966: 563). Dennoch bedeutet die Hanse im landläufigen Verständnis keine konkrete politische Organisationsform, sondern vielmehr ein heterogenes Kulturphänomen, eine „Handels- und Lebensform“ (SCHÜMER 2009: 371), eine Kulturgemeinschaft, die trotz ihrer amorphen Gestalt „500 Jahre im Ostund Nordseeraum wirksam war und für zwei Jahrhunderte die Entwicklung dieser Region mitbestimmt hat - wirtschaftlich, politisch und kulturell“" (SCHILDHAUER 1984: 239). Mit Methoden der traditionellen positivistischen Geschichtsforschung, die auf die Beschreibung konkreter politischer Ereignisse und linearer, kontinuierlicher, eindeutig erfassbarer Entwicklungen hinzielt, ist dem historischen Phänomen der Hanse nicht beizukommen (vgl. SCHÜMER 2009: 370).

$\mathrm{Zu}$ einem Erinnerungsort wurde die Hanse beinahe sofort nach ihrer Auflösung 1669, nachdem Lübeck, Bremen und Hamburg ein Handelsbündnis nach dem Vorbild der Hanse, die sogenannte Hanseatische Gemeinschaft, eingegangen waren. ${ }^{10}$ Die deutsche Erinnerung an die Hanse durchlief mehrere Phasen. Nach dem Dreißigjährigen Krieg verfiel sie für mehr als zweihundert Jahre in einen Zustand der Latenz. Sie lebte erst gegen Mitte des 19. Jahrhunderts wieder auf, diesmal im nationalistischen Geiste. Diese Auffassung wurde u. a. durch die Reflexion von Jacob Grimm angeregt, der die Hanse für einen Inbegriff des Deutschtums hielt (vgl. Hackmann 2015: 85). Mit der Gründung des Deutschen Kaiserreichs 1871 fiel der Beginn der systematischen Erforschung der Hansegeschichte zusammen, wobei die Hanse

10 Im deutschen Sprachgebrauch unterscheidet man daher (wenn auch nicht immer konsequent) zwischen den Bezeichnungen „hansisch“ und „hanseatisch“. Das Adjektiv „hansisch“ bezieht sich auf die „eigentliche“ Hanse, die ihre Blütezeit im Spätmittelalter (ca. 1250-1400) erlebte, „hanseatisch“ dagegen - auf die Nachwirkung bzw. das Nachleben der Hanse nach 1669. „Hanseatisch“ im Geiste war somit die Fortführung der hansischen Tradition, die in erster Linie in den drei Städten Bremen, Lübeck und Hamburg gepflegt wurde. Vgl. https://www. abendblatt.de/region/lueneburg/article108237689/Hanseatisch-ist-nicht-hansisch.html (06.12.2018). Im Polnischen dagegen gibt es nur das Adjektiv „hanzeatycki“, das beide Bedeutungen: „hansisch“ und „hanseatisch“ umfasst. 
„zu einem integralen Teil der deutschen Nationalgeschichtsschreibung“wurde (ebd.: 90). Die Tatsache, dass eine Vielzahl von ethnischen Gruppen zu jener mittelalterlichen Wirtschaftsund Kulturgemeinschaft einen Beitrag leistete, wurde schlichtweg ignoriert. Die kollektive Erinnerung an die Hanse spielte auch eine wichtige Rolle im deutschen kolonialen Diskurs. Die Notwendigkeit, neue Gebiete in Übersee zu gewinnen, wurde unter Berufung auf die vergangene Pracht, Stärke und Dominanz der Hanse im Ostseeraum begründet und die Hanse als Vorbild für eine neu zu gründende deutsche Kolonialmacht beschworen (vgl. SURYNT 2007: 30). In der Ära des Reichskanzlers Otto von Bismarck (1871-1890) sollte die Erinnerung an die Hanse den Mangel an „richtigen“ Kolonien und den sich daraus ergebenden deutschen Minderwertigkeitskomplex kompensieren (vgl. SCHÜMER 2009: 383). Gleichzeitig legitimierte sie die deutsche Ostkolonisation, die zum Ziel hatte, historische deutsche Gebiete, die früher im Einflussbereich der Hanse standen, zurückzuerobern und wieder zu zivilisieren (vgl. Belzyt 2014). Wie SCHÜMer (2009: 385) bemerkt, wurden die Historiker der Hanse, die sich im „Hansischen Geschichtsverein“ zusammengeschlossen hatten, in der Zeit des Nationalsozialismus ,zu üblen Propagandisten deutscher Kulturhoheit gegenüber den Slawen und Balten“. Sie lieferten Argumente für die Herstellung eines "großdeutschen Raums“, der mit dem Kulturraum der Hanse zusammenfallen sollte.

Die Erinnerung an die Hanse ist bis heute im Wandel begriffen. Nach dem Zweiten Weltkrieg wurde die Hanseforschung in der DDR fortgesetzt, allerdings unter den Vorzeichen des Sozialismus. Nun galt es, die Entwicklung der Hanse als „Geschichte von Klassenkämpfen“ in den Hansestädten aufzufassen und den Beitrag der ,werktätigen Menschen“ zum Aufbau des gemeinsamen Wohlstands herauszustellen (vgl. Schild hauer / Fritze / STARK 1972: 9). Man wollte sich von den Darstellungen, die aus der Feder „bürgerlicher Historiker“ stammten und „besonders seit der Wende vom 19. zum 20. Jahrhundert [...] von der Großmachtideologie des deutschen Imperialismus" durchtränkt waren (ebd.: 8), ausdrücklich distanzieren. Nach der Wende 1989 erhielt die Erinnerung an die Hanse mit der europäischen Integration, insbesondere mit der Osterweiterung der Europäischen Union, einen neuen Schub. In der neueren Geschichtsschreibung und Publizistik gerieten die Analogien zwischen den modi operandi der Hanse und den der Europäischen Union in den Blickwinkel. Allerdings wurde die Idee der deutschen Vormachtstellung in der Ostseeregion als ideologischer Ballast, der die Hanse als Gedächtnisort belastet, verworfen. Heute erscheint die Hanse eher als Symbol fruchtbaren Kulturaustauschs und wirtschaftlicher Zusammenarbeit zwischen den Städten und Ländern des Ostsee- und Nordseeraums. Die Geschichte der Hanse liefert auch Beispiele und Vorbilder für die Gestaltung internationaler Beziehungen aufgrund von Verhandlungen, Kompromissen und friedlicher Beilegung von Konflikten (vgl. Dollinger 1966: 486), für „dezentrale und übernationale Kooperation, für die Vereinheitlichung von Rechts- und Handelsnormen, für demokratische Strukturen" (HACKMANn 2015: 86). In der „unorganische[n], fast nicht greifbare[n] Struktur dieses Gebildes“(Dollinger 1966: 13), die mit der postmodernen Figur eines Rhizoms zu vergleichen ist, ${ }^{11}$ sieht man ein Modell,

11 Diese Struktur umfasste ein in ganz Nordeuropa weitverzweigtes Netz von Handelskontakten, die inoffiziell durch Verwandtschaftsbeziehungen zwischen den lokalen hansischen Kaufmannsfamilien gestärkt und gefördert wurden. Dieses „Rhizom“ gründete auf althergebrachten „Kontakten, Gewohnheitspraktiken 
nach dem auch heute der freie Verkehr von Waren, Personen, Dienstleistungen und Kapital auf dem europäischen Binnenmarkt erfolgt. Eine Analogie zur Hanse besteht darin, dass die Europäische Union, jener mittelalterlichen Wirtschaftsgemeinschaft nicht unähnlich, ein dezentralisiertes, übernationales Gemeinwesen darstellt, „dessen Grenzen und Kompetenzen wir nur schwer definieren können" (SCHÜMER 2009: 386).

Nicht zuletzt kommt die Erinnerung an die Hanse sogar im kommerziellen Bereich zum Ausdruck. Der Name selbst wird nämlich seit der Bismarckischen und Wilhelminischen Ära bis heute als eine Handelsmarke verwertet: in Deutschland und außerhalb, darunter in früheren Hansestädten wie Danzig bzw. Gdańsk. Das „Hanse-Etikett“ verdankt seinen Marktwert den positiven Assoziationen mit Wohlstand, langer Tradition und kaufmännischer Tüchtigkeit, aber auch mit Weltoffenheit und Selbstsicherheit; der lokale Patriotismus spielt dabei auch eine Rolle. Den kommerziellen Wert der Hanse beutet man in Branchen wie Tourismus, Transport, Logistik und Finanzen aus, in denen die Verwendung des Begriffs „Hanse“ als Bestandteil von Firmennamen (z.B. Lufthansa) durch die Konnotationen mit Reisen, Seefahrt und Handel gerechtfertigt wird. Es werden auch viele Produkte verkauft, die den Namen der „Hansa“ führen, ohne mit der Namensgeberin im Zusammenhang zu stehen, z.B. Hansa-Bier, Hansa-Kekse. Allein in der Freien Stadt Danzig gab es Unternehmen wie: Hansa-Bank, Hansa-Buchhandlung, Hansa-Drogerie, Hansa-Likörfabrik, Kunstmöbelfabrik „Hansa“, Badeanstalt „Hansabad“, Hansa-Sägewerke, Hansa-Lichtspiele, Pianofabrik „Hansa“ u.v.m. ${ }^{12}$

Somit ist die Hanse als Erinnerungsort ein historisch wandelbares Konstrukt, das unterschiedlich interpretiert wird - je nachdem, wer von ihm spricht, wann, wo und zu welchem Zweck. Dennoch bleibt der Kern dieses teils imaginären, teils faktenbasierten Gebildes konstant und lässt sich als überzeitliches Stereotyp bezeichnen. ${ }^{13}$ Dem Erinnerungsort „Hanse“ werden eine Reihe von mehr oder weniger dauerhaften Merkmalen zugeschrieben, von denen einige abhängig von den äußeren Umständen - etwa dem historischen oder tagespolitischen Zusammenhang - im Diskurs stärker zur Geltung kommen, während andere vorläufig in den Hintergrund treten. Was macht also den stereotypen Kern des Erinnerungsortes der Hanse aus?

Eine stereotype Vorstellung der hansischen Gemeinschaft wird sowohl in geschichtswissenschaftlichen Texten aus verschiedenen Epochen als auch in den vorgenannten Danziger Flugschriften wiederholt evoziert. Schildhauer, Fritze und Stark, Autoren der bereits zitierten Hanse-Monographie aus der DDR, äußern sich zu ihrem Forschungsgegenstand wie folgt - allerdings in vollem Bewusstsein, dass sie ein Stereotyp bemühen:

„Noch immer künden zahlreiche großartige Bauten in den Hansestädten, stolze Rat- und Bürgerhäuser, hoch aufragende Kirchen und wehrhafte Stadttore vom Wirken der Hanse sowie vom Können

und Handelsbräuchen“" (SchÜmer 2009: 386). Vgl. auch Schildhauer (1984: 102-103) und Dollinger (1966: 220-221). Beide Autoren besprechen diverse Organisationsformen des Fern- und Zwischenhandels im Rahmen der Hanse, darunter die Handelsgesellschaften.

12 Vgl. Adressbuch für Danzig und Vororte 1925, S. 136. Wie aus dem Vergleich mit späteren Adressbüchern hervorgeht, blieben die meisten Unternehmen während der gesamten Dauer der Freien Stadt Danzig bestehen, vgl. etwa Danziger Einwohnerbuch 1937/38 mit allen Vororten und Zoppot, S. 149.

$13 \mathrm{Zu}$ den Überschneidungen und Unterschieden zwischen den Begriffen „Erinnerungsort“ und „Stereotyp“vgl. OrŁowsKi (2012: 111-112). 
hansestädtischen Bürgertums. Der Name der Hanse lebt in mannigfacher Weise bis heute fort. Die kühnen Fahrten hansischer Seeleute auf ihren seetüchtigen Koggen haben ebenso wie die Taten der Seepiraten in zahlreichen Sagen und literarischen Verarbeitungen immer erneut ihren Niederschlag gefunden." (Schildhauer / Fritze / Stark 1972: 265)

In diesem kurzen Zitat treffen alle populären Vorstellungen und Schlagworte, die man mit der Hanse konnotiert, aufeinander: die charakteristische Architektur der Backsteingotik, die Kogge als typisch hansisches Handelsschiff, ${ }^{14}$ allen voran aber ein Menschentyp, der den „Geist der Hanse“, die Mentalität und das Weltbild dieser Kulturgemeinschaft verkörpert. Dem Stereotyp eines Hanse-Menschen lassen sich zwar Vertreter mehrerer Berufe zuordnen: „wagemutige Seefahrer" (SCHÜMER 2009: 370), Bürgermeister und Ratsherren, städtische Chronisten, „fromme Altarmaler“ (ebd.) und Bildschnitzer, aber den Prototyp macht zweifellos ein wohlhabender Kaufmann aus, der in seinem Kontor über den auf dem Pult ausgebreiteten Rechnungsbüchern sitzt.

Karl Pagel zeichnet in seiner deutlich nationalistisch orientierten Hanse-Monographie aus den 1940er Jahren folgendes Porträt von Hanse-Kaufleuten - ahistorisch und stereotyp:

„Sie stehen vor uns als kraftvolle Gestalten, gesund und nüchtern, mit beiden Füßen auf der Erde, selbstsicher, zupackend, lebenskräftig, genußfroh und unproblematisch. Wir sehen sie durch ihre Städte und ihre Märkte schreiten, sehen sie in ihren Häusern, Speichern und Werkstätten ihrem Tagewerk nachgehen, sehen sie auf ihre Schiffe steigen und die See bezwingen, sehen, wie sie auf ihren Mauern stehen, wehrhaft und bürgerstolz, wie sie zu Rate sitzen, wie sie mit Freund und Feind Verhandlungen pflegen, wie sie Gericht halten und Kauf schlagen, in der Heimat und in der Fremde, wie sie sich den Freuden ihrer Festtage hingeben, und sehen, wie sie in ihren stolzen Kirchen vor Gott hintreten und an seinen Altären in frommer Demut um Vergebung ihrer Sünden bitten, ein aufrechtes Geschlecht, das nicht gern den Nacken beugt - Menschen, denen wir glauben dürfen, daß auf ihren Schultern das stolze Gebäude der Hanse sicher ruhte [...]“. (PAGEL 1942: 392)

Ein stereotyper Hanse-Mensch lässt sich somit als nüchterner, pragmatischer, wirtschaftlich denkender und unternehmungslustiger, womöglich etwas berechnender Kaufmann vorstellen. Nach SCHILDHauer (1984: 149) ist die Lebensauffassung eines solchen Menschen durch „das Verlassen auf die eigenen Kräfte, das Wissen, auf Grund eigener Fähigkeiten etwas zu erreichen, die Risikobereitschaft, aber auch rationelles Abwägen, das Streben nach Autorität“ gekennzeichnet. Diese „kaufmännisch-rechnerische” (ebd.) Denkweise beeinflusste sogar die persönliche Einstellung zu Glaubensfragen. Es ist bemerkenswert, welche Eigenschaften eines Hanse-Menschen Karl Pagel 1942 Jahren hervorhebt: Stolz, Mut, Wehrhaftigkeit, Verbissenheit, aber auch Selbstdisziplin, Gemeinschaftsarbeit und Treue gegenüber der ,großen Vergangenheit" der mit dem großdeutschen Raum identifizierten Hanse (vgl. PAGEL 1942: 526).

Im neueren, postmodernen Diskurs geraten andere Merkmale des hansischen Wesens in den Vordergrund: die bereichernde Erfahrung von Fremdheit, wie sie jedem angehenden

14 Die Kogge war ein Einmaster mit flachem Boden und bauchigem Rumpf. Sie war langsam, aber stabil und hatte eine hohe Ladekapazität. Im Notfall konnte das Schiff mit Kanonen ausgerüstet werden und der Verteidigung vor Piraten dienen, vgl. Samsonowicz (1958:58-62), Schildhauer (1984: 36). Danzig bzw. dessen als Rechtstadt bezeichnetes Viertel benutzte bis ins 14. Jahrhundert hinein ein Siegel, das eine Kogge darstellt - „Symbol des kaufmännischen Erfolgs“ (LoEw 2011: 46). 
Kaufmann, der in einem überseeischen Kontor eine Lehre antrat, zuteilwurde; die Bereitschaft zum Kulturaustausch, der aber gegenseitig verlief und sich nicht auf die deutsche „Zivilisierung" des (östlichen) Ostseeraums beschränkte, wie es die Historiker des Zweiten und Dritten Reiches darstellten. ${ }^{15}$

Somit umfasst das Stereotyp der Hanse einerseits Artefakte materieller Kultur (die Kogge, Bauwerke der Backsteingotik), andererseits - das nur schwer fassbare Weltbild der hansischen Kulturgemeinschaft, bei der Stolz und ausgeprägtes Selbstwertgefühl, Tüchtigkeit, Unternehmensgeist und nüchterner Pragmatismus hoch im Kurs standen.

\section{Bezüge zur Hanse in den touristischen Flugschriften aus der Freien Stadt Danzig}

Die Mitgliedschaft Danzigs in der Hanse ist seit 1361 belegt (vgl. Loew 2011: 49). Selbst wenn das „Goldene Zeitalter“ der Stadt an der Mottlau (1454-1655) mit dem Niedergang der Hanse zusammenfällt und den intensiven wirtschaftlichen Beziehungen zu den Niederlanden zu verdanken ist, hat die Teilnahme am hansischen Bündnis wichtige Grundlagen für den späteren Aufstieg Danzigs zu einer Handelsmacht geschaffen und das kollektive Gedächtnis der Danziger nachhaltig geprägt.

In der Freien Stadt Danzig wurde das Hansische, dem man hohe politische Relevanz zuschrieb, als Teil des kulturellen Selbstverständnisses wahrgenommen. Diese Haltung kam nach dem Friedensvertrag von Versailles (1919) deutlich zum Ausdruck. In den Entwürfen einer Verfassung für das neue Staatswesen, die fast drei Jahre lang (1919-1922) verhandelt wurden, bestand man auf der offiziellen Bezeichnung „Freie und Hansestadt Danzig “16 - ein Postulat, das der Völkerbund ablehnte (vgl. MACIEJEwSKi 2017: 90). Der Name wurde nach der 1939 erfolgten rechtswidrigen Eingliederung der Freien Stadt Danzig in das Reichsgebiet dennoch durchgesetzt: 1940 hat der Reichsstatthalter in Danzig-Westpreußen „der Stadt Danzig das Recht verliehen, künftig die Bezeichnung,Hansestadt' zu führen" (Der Danziger Vorposten 20.12.1940, S. 6). Damit wurde Danzigs ,neue Stellung im Rahmen des künftigen deutschen Aufbauwerkes im Osten äußerlich besonders unterstrichen“ (ebd.) - d.h. Danzig sollte zu einem Zentrum des Deutschtums im Osten werden. ${ }^{17}$ In der Zwischenkriegszeit sollte

15 Vgl. das folgende, für die damalige Zeit typische Zitat: „Am Anfang des deutschen Ostwegs steht die Gestalt Heinrichs des Löwen und die Gründung Lübecks. Heinrich der Löwe - das ist die gesammelte Kraft des Sachsenstammes, Lübeck - das ist der Kräftestrom, den das junge deutsche Städtebürgertum in die ungeformte östliche Weite entsendet." (PAGEL 1942: 35)

16 So hieß die Stadt sowohl im Projekt des Oberbürgermeisters Heinrich Sahm vom 07.09.1919 als auch im Entwurf des sog. Unterausschusses zur Vorbereitung der Verfassung vom Januar 1920 (vgl. MACIEJEw SKI 2017: 73, 84).

17 Dieser Gedanke tauchte in der deutschen Öffentlichkeit natürlich schon viel früher auf. Einen indirekten, aber vielsagenden Beweis dafür liefert etwa die Gründung der ersten deutschen Studentenverbindung in Danzig, die sich „T! Hansea“ nannte (vgl. Daniluk 2011a: 47). Diese sog. Turnerschaft entstand bereits im August 1904, noch bevor die neu gegründete Königlich Preußische Technische Hochschule Danzig im selben Jahr den Lehrbetrieb aufnahm. Hinter der Wahl Danzigs als akademische Neugründung stand die Absicht, das „deutsche Element“ im Osten zu stärken; auch in der späteren Freien Stadt Danzig sollte die Technische Hochschule ein Bollwerk des Deutschtums sein (vgl. Daniluk 2011b: 50). In Danzig waren bis zum Zweiten 
die im öffentlichen Diskurs immer wieder beschworene hansische Vergangenheit Danzigs daran erinnern, dass die Stadt vom Deutschen Reich zu Unrecht abgetrennt wurde.

In den touristischen Flugschriften und Broschüren aus der Freien Stadt Danzig, die jenen Diskurs mitgestalten, werden die Relationen zum Stereotyp der Hanse grundsätzlich nach drei Verfahren hergestellt: durch explizite Bezüge, durch versteckte Anspielungen und mit Hilfe von visuellen Elementen, die die Wirksamkeit des verbalen Textes unterstützen.

Sämtliche mir vorliegenden Ephemera, die in die Zeit 1920-1939 zu datieren sind (wobei die genaue Jahreszahl selten angegeben wird), betonen Danzigs Zugehörigkeit zur Hanse und verwenden just denjenigen Namen, der dem Freistaat auf internationaler Ebene verweigert wurde: „Danzig, die freie Hansestadt“ (5093/17), „alt[e] Hansestadt Danzig“ und „altehrwürdige Hansestadt Danzig“ (5237/17). ${ }^{18}$ Auch in Flugschriften, die schwerpunktmäßig für das Kurbad Zoppot werben und Danzig mit seinen Sehenswürdigkeiten nur nebenbei bemerken, erscheint der Name Danzig mit dem „hansischen“ Attribut ausgestattet: „Das Weltbad Zoppot liegt an der Ostsee, 20 Minuten von der alten ehrwürdigen Hansastadt Danzig entfernt“ (4675/15). Das Toponym „Danzig“ mit der Beifügung „Hansestadt“ und den Adjektiven: „alt“, „,hrwürdig“ bzw. ,altehrwürdig“ erstarrt somit zu einer Art sprachlichen Klischee. Die Stadt wird mit dem „wehrhafte[n] Hanseatengeist der königlichen Kaufleute“ (5093/17) identifiziert, und ihre nach wie vor in Betrieb befindlichen Hafenanlagen ,erzählen von Zeiten hansischer Macht" (4727/15). Die Texte der Flugschriften heben die vergangene Pracht und die dem Fernhandel zu verdankende Macht Danzigs hervor, deren Spuren und Überreste sich bis dato (d.h. bis zur Zwischenkriegszeit) erhalten haben. Danzig wird als „Handelsstadt von hervorragender Bedeutung“ (P6/30) bezeichnet oder als „die Königin der Ostsee" (2652/05) personifiziert - Attribute, die man mit dem Begriff der Hanse assoziiert.

Deutliche Anspielungen auf die Hanse finden sich in Bezügen zu den Charaktereigenschaften, Lebenseinstellungen, Beschäftigungen und Leistungen der Danziger Bürger, die Träger des hansischen Geistes waren:

- „Gegenüber der Langen Brücke künden Speicherbauten von kaufmännischem Geschick und weitverzweigtem Handel mit fernen Ländern." (4727/15)

- „Vergangenheit und Gegenwart reichen sich unter seinem [des Krantors, K.L.] Angesicht die Hand und suchen den Weg in die Zukunft. Man erlebt es in den Räumen des Uphagenhauses, die den Atem der Hanseatenzeit in sich bewahrt haben und in dessen nächster Umgebung der Kaufmannsgeist unserer Zeit seine Bankhäuser und Schiffahrtskontore errichtet hat." (P4/1936)

- „Der hier abgebildete $80 \mathrm{~m}$ hohe Kran der Schichauwerft ist ein prächtiges Sinnbild des aufwärts strebenden Danziger Kaufmannsgeistes.“ (5271/18)

An einer anderen Stelle wird „fleißiger Bürgersinn des kunstfreudigen Mittelalters“ erwähnt (5093/17). Häufig greifen die Verfasser der Flugschriften und Broschüren zur Figur der

Weltkrieg zahlreiche, zumeist deutsche, Studentenverbindungen tätig. Wenn man bedenkt, dass diese Korporationen junge Männer mit einer klaren Weltanschauung und festen politischen Überzeugungen vereinigten, so leuchtet ein, dass die Mitgliedschaft in der „T! Hansea“, deren Name an sich bestimmte Symbole und Werte vermittelt, einem politischen Bekenntnis gleichkam.

18 In den Sammlungen der PAN Biblioteka Gdańska befinden sich außerdem auflagenstarke Werbeschriften aus den Jahren 1941-1942, in denen der damals offizielle Name „Hansestadt Danzig“ als feste Wortfügung im Titel steht. Aufgrund der Datierung gehören sie jedoch nicht mehr zu dem hier besprochenen Textkorpus. 
Personifikation und schreiben der Stadt Danzig typische Charaktereigenschaften eines hansischen Kaufmanns zu:

- „Danzig an der Ostsee, Jahrhunderte prägten das charaktervolle Antlitz dieses deutschen Stadtwesens: wehrhaft, trutzig, handelsklug, regsam, kunstfreudig, vergangenheitsbewußt in seiner Kulturtreue.“( $(4727 / 15)$

Dabei sind das „Vergangenheitsbewusstsein“ und die „Kulturtreue“ im obigen Zitat eine rückwärtsgewandte Projektion von Einstellungen, die aus der damaligen historischen Perspektive für Danzig als „deutsches Stadtwesen“ wünschenswert erschienen.

Erwähnenswert ist in diesem Kontext auch die Präsenz von Bildern, die der stereotypen Vorstellung eines Hanse-Kaufmanns entsprachen, in der visuellen Sphäre der Gebrauchskunst, nämlich auf offiziellen Banknoten der Freien Stadt Danzig. Ausgewählte Porträts der Danziger Fernhändler, die von Hans Holbein d. J. (1497/98-1543) gemalt wurden, ${ }^{19}$ stehen hier gleichsam pars pro toto für die gesamte Danziger Kaufmannschaft aus ihrem „goldenen Zeitalter"; auf Geldscheinen reproduziert, personifizieren sie, so FRIEDRICH (2010: 198), den Danziger Handel überhaupt.

Obligatorisch werden in allen an deutsche Touristen gerichteten Flugschriften die berühmtesten Danziger Sakral- und Profanbauten als Sehenswürdigkeiten erwähnt, die man mit dem Erscheinungsbild einer prototypischen mittelalterlichen Hansestadt assoziiert:

- „Die Gesamtansicht Danzigs vom ,Bischofsberg' ist ein mittelalterliches Städtebild von packender Großartigkeit. Das Braunrot der Jahrhunderte alten Backsteinbauten, das dunkle Grün der die Stadt umgürtenden Fichtenwälder und das satte Blau der Ostsee klingen in wundervoller Harmonie zusammen. Beherrscht wird das ganze Bild durch die massige Wucht St. Marien’s, der fünftgrößten Kirche der Welt und die kühne Schlankheit des Rathausturmes, die beiden unvergleichlichen Wahrzeichen der alten Hansestadt." (5271/18)

- $\quad$ „Drei Wahrzeichen dieser altehrwürdigen Stadt: Marienkirche, Krantor, Rathaus.“ (4675/15)

- „Die drei Wahrzeichen Danzigs Rathaus, Marienkirche und der Kran.“ (5271/18)

- „Drei Wahrzeichen: Rathaus, St. Marien, Krantor.“ (5108/17)

Es fällt auf, dass in diesen Aufzählungen das Wahrzeichen des heutigen Gdańsk, nämlich der Neptunbrunnen fehlt. Dies ist dadurch zu erklären, dass diese Figur erst zu Beginn des 17. Jahrhunderts im Stil des niederländischen Manierismus errichtet wurde, also mit der hansischen Baukunst nichts zu tun hat. ${ }^{20}$ Seinen Rang als das berühmteste Wahrzeichen der Stadt an der Mottlau erlangte der Neptunbrunnen erst in der Nachkriegszeit.

19 Es handelt sich um das auf dem 10.000-Mark-Schein der Freien Stadt Danzig vom Jahr 1923 abgedruckte Porträt Johann Schwartzwaldts, das unter dem Titel Bildnis eines Danziger Kaufmannes im damaligen Stadtmuseum in Danzig aufbewahrt wurde; im Zweiten Weltkrieg ist das Gemälde verschollen. Zwei Banknoten der deutschen Reichsbank ungefähr aus der gleichen Zeit schmückte wiederum das reproduzierte Bildnis des Danziger Hansekaufmanns Georg Giese im Londoner Hansekontor, dem Stahlhof (vgl. FrIEDRICH 2010: 198, 201).

20 Zudem waren die polnischen Adler, die seit dem 18. Jahrhundert das eiserne Gitterwerk um den Brunnen herum verzierten, den Nationalsozialisten ein Dorn im Auge - bis sie 1935 beschädigt wurden (vgl. den Eintrag „Fontanna Neptuna“ im Online-Lexikon Gedanopedia). Ansonsten wurde der Neptunbrunnen in der Ikonographie der Freien Stadt Danzig immer so dargestellt, dass man die Adler nicht sehen konnte. 
Ansonsten ist die Wahl der Bauwerke, die in den angeführten Textstellen genannt werden, keineswegs zufällig. Das Rathaus ist im wörtlichen Sinne der Sitz der (autonomen) Stadtverwaltung und steht auch symbolisch für die Unabhängigkeit, Selbstbestimmung und wohlgeordnete Organisation einer Hansestadt. Das Krantor erweckt offensichtliche Assoziationen mit Fernhandel, überseeischen Reisen, Schiffen mit kostbarer Ladung, die den Hafen des mittelalterlichen Danzigs anliefen. ${ }^{21}$ Die Marienkirche hingegen erfüllte dieselbe Funktion wie alle hansestädtischen Hauptkirchen, die von der lokalen Kaufmannschaft nicht (nur) aus religiösen, sondern vielmehr aus Prestige- und rein praktischen Gründen gestiftet wurden:

„Die hohen Kirchtürme der Seestädte waren viele Kilometer vom Meer her zu sehen und kündigten den Seeleuten, lange bevor sie im Hafen anlegten, an, daß Haus und Herd wieder erreicht waren. Deshalb waren diese Kirchen in den Augen der Hansen sogar das Symbol ihrer Vaterstadt." (Dollinger 1966: 355)

Natürlich sollte ein so repräsentatives Bauwerk wie die Danziger Marienkirche auch den Stolz, den Reichtum und die Macht der hier ansässigen Kaufleute manifestieren.

In den Beschreibungen der Bauwerke, die als Metonymien der Stadt Danzig auftreten, wiederholen sich Adjektive („prächtig“, ,riesig“", ,altehrwürdig“, ,massig“, ,wuchtig“, „gewaltig“, „mächtig“, „kühn“, „wehrhaft“) und attributiv verwendete Substantive („die massige Wucht St. Marien's“, „die kühne Schlankheit des Rathausturmes"). Die Adjektive und die Köpfe der Substantivphrasen („massige Wucht“, „kühne Schlankheit“) haben einen axiologischen Charakter: Sie konnotieren positive Werte, sollen aber auch das Gefühl von Bewunderung, Begeisterung und Einschüchterung angesichts der vergangenen, aber immer noch nachwirkenden Macht der Hanse erwecken. Die angeführten Lexeme bilden dabei eine Art wertende Kollokationen bzw. sprachliche Klischees. So wird der Marienkirche erwartungsgemäß die Eigenschaft der "massigen Wucht“ zugeschrieben, während der Turm des Rechtstädtischen Rathauses „zierlich-schlank“ (5093/17) ist.

Die Wirkungsmacht der symbolischen Bauwerke, die dem hansischen Erbe Danzigs angehören, ist umso größer, wenn die Beschreibungen durch Fotos bekräftigt werden - ein unverzichtbares Element aller den Fremdenverkehr fördernden Werbeschriften. Im Hinblick auf die Wahl der Bilder fügen sich die besprochenen Ephemera in den visuellen Propaganda-Diskurs der Freien Stadt Danzig nahtlos ein, zumal die Texte unter den Bildern oft nicht nur die hansische, sondern auch die „rein deutsche“ Herkunft der Bauten erwähnen - gemäß der nationalistischen Tendenz, die Hanse mit dem Deutschtum gleichzusetzen:

21 Das Krantor als das wichtigste Gebäude, das man mit der Freien Stadt Danzig assoziierte, war im ikonischen Gedächtnis nicht nur der Danziger Bevölkerung, sondern auch im Ausland tief verwurzelt. Von dieser Präsenz zeugt u. a. die Wahl dieses Bauwerks, dessen Gestalt in das Logo der 1924 ausgerichteten II. Danziger Internationalen Messe integriert wurde. In der Zeitung Danziger Volksstimme vom 25.04.1924 wird der im Wettbewerb für die Werbemarke der DIM preisgekrönte Entwurf des Danziger Kunstmalers Curt Ziesmer wie folgt kommentiert: „Dieser Künstler hat sich das Krantor ausgewählt und die Kontur dieses alten Baues, der schon längst zum Wahrzeichen Danzigs geworden ist, für die drei Buchstaben DIM D(-anziger I-nternationale) M-esse) in außerordentlich geschickter Weise [...] ausgewertet“" (Danziger Volksstimme, Ausgabe 97 vom 25.04.1924, S. 5; Schreibweise wie im Original). Zu dieser Werbemarke vgl. den Beitrag von Aneta Kwiatkowska in diesem Band. 
- „Danzig an der Ostsee, Jahrhunderte prägten das charaktervolle Antlitz dieses deutschen Stadtwesens“ (Beschreibung unter dem Foto des Langen Marktes, mit dem Rechtstädtischen Rathaus im Hintergrund, 4727/15);

- „Die Große Mühle (1349) ist ein eindrucksvolles Denkmal der Baukunst des Deutschen Ritterordens, der auch der Erbauer Danzigs ist." (5271/18)

Auch wenn man den deutschen Ursprung der Danziger Architektur nicht explizit erwähnt, wird er durch die eingesetzten rhetorisch-visuellen Mittel suggeriert. So kündet der Text unter dem Foto der Marienkirche Folgendes:

- „Danzig - das Kleinod nordischer Städteschönheit! Alte deutsche Glockenlieder trägt der Seewind über waldige Höhen." (4727/15)

Der Text gibt keine Auskunft darüber, von welchem Kirchturm die Glockenlieder ertönen. Die Zusammenstellung der Phrase „alte deutsche Glockenlieder" mit der abgebildeten Marienkirche (vgl. Abb. 3) weist aber eindeutig darauf hin, dass die Melodien durch die Glocken dieses Gotteshauses gespielt werden, das folgerichtig auch ein deutsches Bauwerk sein muss.

Selbst in den Passagen, die ausdrücklich die Gegenwart, die moderne Technik und die Schiffbauindustrie in der Freien Stadt Danzig thematisieren, kommen Anknüpfungen an die Hanse vor. In derselben Broschüre stößt man auf ein Foto mit dem Untertitel „Verladen von Kohle im Danziger Hafen“ und mit folgendem Kommentar (vgl. Abb. 4):

- „Weitgestreckte Hafenanlagen, gerüstet von der Technik unserer Zeit, wechselnde Bilder: Werften, gewaltige Schwimmdocks, riesige Kräne, Dampfer mit Flaggen aller Länder, Segler, mächtige Lade- und Löscheinrichtungen und endlich die Westerplatte mit ihrer eigenartigen Bestimmung erzählen von Zeiten hansischer Macht und Seegeltung und zugleich von Schicksalen der Gegenwart." $(4727 / 15)$

Die Aufzählung von stichwortartigen, klischeehaften Hinweisen auf die vergangene Macht der Hanse (mit den stereotypen Adjektiven "gewaltig" und "mächtig") wird hier mit expliziten oder verschleierten Bezügen zum gegenwärtigen Schicksal Danzigs kontrastiert - einer Stadt, die man als erniedrigtes, gedemütigtes und degradiertes Opfers des „Diktats von Versailles“ (4727/15) darstellt. Bemerkungen über die stolzen Danziger Kaufleute, über den Reichtum, über die Glanzzeit der Architektur und Kunst - das also, was man unter der klischeehaften Nominalphrase "gewaltige Vergangenheit" subsumiert, wird solchen Ausdrücken gegenübergestellt wie: „schmerzvolle Tragik des Zusammenbruches“ (5093/17; gemeint ist der Vertrag von Versailles und die Gründung der Freien Stadt Danzig), ,eine schicksalschwere [sic] Gegenwart“ (ebd.) oder „Schicksale der Gegenwart“ (4727/15). Die Referenzen auf die vergangene Macht sollen das historische Unrecht und das Leid, das der stolzen Hansestadt an der Mottlau widerfahren ist, umso stärker zur Geltung kommen lassen. Dahingegen vermitteln Hinweise auf eine „große Zukunftsaufgabe“ (5093/17), „Verpflichtung“( (ebd.) und „die brennende Frage der Gegenwart“ (ebd.) den Gedanken, dass Danzig wieder in das Deutsche Reich eingegliedert werden soll. Die Texte der Flugschriften richten an ihre Rezipienten einen zu jenem Zeitpunkt unmissverständlichen Appell: 


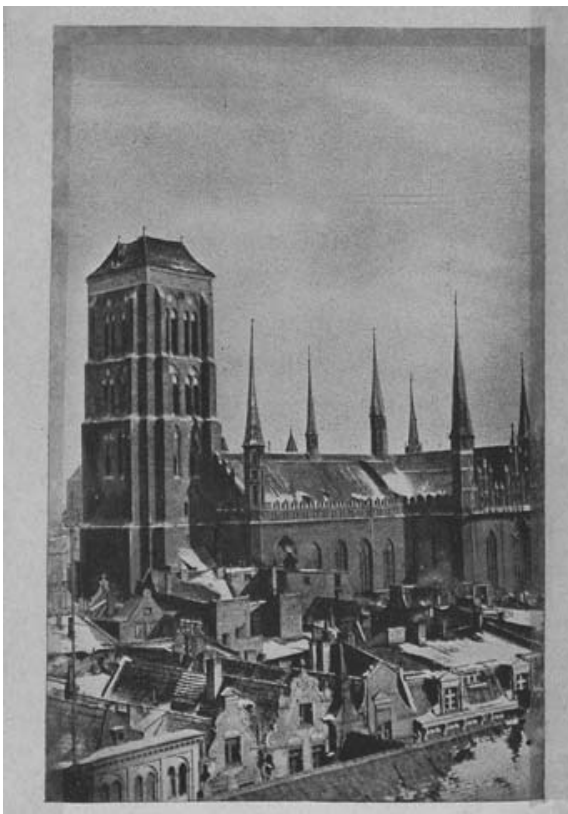

St. Marien in Danzig

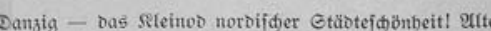
beutíde Glodentieder trägt ber Geeminฎ itber malbige

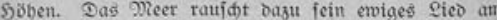

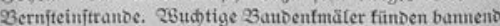
in finumer Svracte: Diefe Staot ift ein eimsigartiges (frTebria! Sier lebt uno webt Geífidte und Sunit, bier lodt

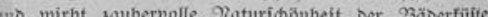

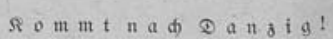

Fuskünffe über bie Theife nady Dany

Abb. 3. Faltblatt „Danzig“, Innenseite $(4727 / 15)$

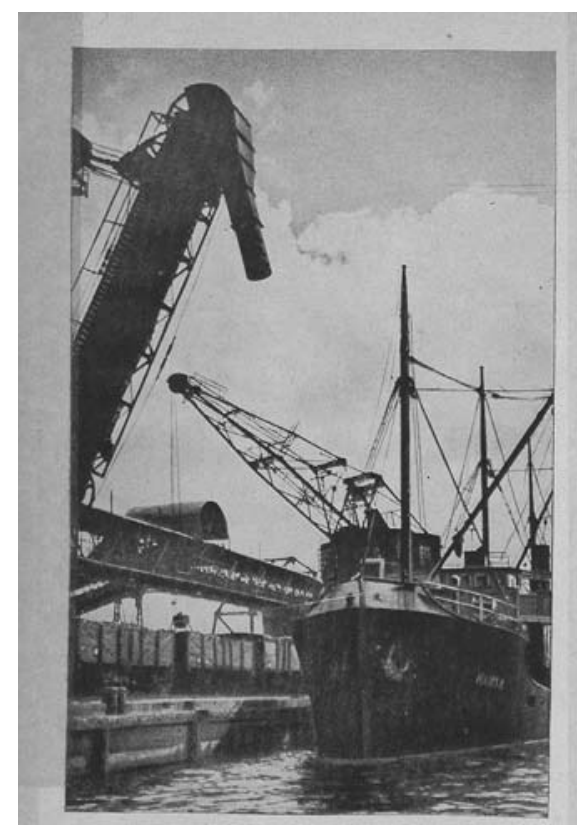

Derlaben oon Joble im Danjiger Gafen

2Beitgefiredte Safenantagen, gerïftet von ber Sednit untierer Seit, wedfelnbe 23ilder: 2beriten, gewaltige Combimmoods, tieige Sträne, Dampfer mit Flaggen aller eanoer, Gegler,

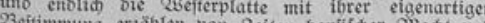

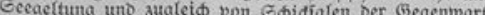

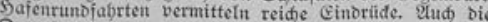

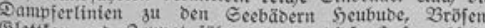
Oroutat unt 3oppot fubren oura bicie bajengebiete.

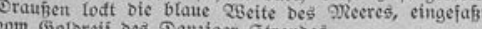

Betlin, 2Inter Den Rinoen 16, burrh bie

Abb. 4. Faltblatt „Danzig“, Innenseite $(4727 / 15)$

- „Und wer als Fremder durch Danzigs Straßen geht, ergriffen vor Sankt Mariens stummer Wucht steht und die Traumverlorenheit der nächtlichen Frauengasse in seinem Herzen erleben kann, der soll sich mit wachen Sinnen der Gegenwart zuwenden und begreifen lernen, welche Verpflichtung die eindringlich mahnende Schönheit Alt-Danzigs seinen heutigen Menschen auferlegt." $(5093 / 17)$

Beim Anblick des malerischen Stadtbildes darf sich der deutsche Tourist also weder auf rein ästhetisches Erlebnis beschränken noch in nostalgisches Grübeln verfallen, sondern er soll zur Idee von Danzigs Wiederangliederung an Deutschland stehen und diese in die Tat umsetzen. 


\section{Schlussbemerkung}

Die besprochenen touristischen Flugschriften und Broschüren aus der Zeit der Freien Stadt Danzig erfüllen hauptsächlich eine persuasive Funktion. Sie ist mit der analogen Funktion von heutigen Drucken, die in der Tourismus-Branche verbreitet werden, kaum zu vergleichen. Zeitgenössische ephemere Werbetexte, die im Fremdenverkehr zum Einsatz kommen, sollen - im Großen und Ganzen - den Rezipienten zur Besichtigung von bestimmten Orten ermutigen; die dahinter stehende Motivation ist sowohl ein Erkenntnisgewinn (für den potentiellen Besucher) als auch ein kommerzieller Vorteil (für den Auftraggeber des Werbetextes). Die touristischen Ephemera aus der Freien Stadt Danzig sollen hingegen die kollektive Identität ihrer deutschen Adressaten prägen. Im Bewusstsein der Zielgruppe soll das Bild Danzigs als einer rein deutschen Stadt, die vom „deutschen Mutterland" gewaltsam abgetrennt wurde und dennoch ihren ethnischen Wurzeln treu bleibt, gestärkt werden. Diese propagandistische These wird durch die Referenzen auf das Stereotyp der Hanse untermauert, das gleichzeitig auf zwei Ebenen aktiviert wird: der sprachlichen (durch einzelne Lexeme, klischeehafte Phrasen, wertende Attribute) und der visuellen.

Touristische Ephemera, auch wenn sie nicht zu Propagandazwecken gedruckt werden, bieten keinen Platz für umfangreiche, ausgewogene, mehrere Perspektiven berücksichtigende historische Darstellungen der Stadt und Region. Anders als bei Reiseführern in Buchform, müssen sich Verfasser von Flugschriften kurz fassen, auf (ethnische) Verallgemeinerungen und gedankliche Abbreviaturen ausweichen. Als Hilfsmittel bieten sich dabei Erinnerungsorte an: mentale Konstrukte, die bequem einsetzbar sind, weil sie sich in einigen wenigen Stichworten und stereotypen Phrasen aktivieren lassen. Das Beispiel der Hanse in den Flugschriften aus der Freien Stadt Danzig zeigt, dass ein Erinnerungsort eine integrierende und identitätsstiftende Kraft besitzt, er kann aber genauso leicht instrumentalisiert werden, sobald die Emotionen, die er hervorruft, gezielt in bestimmte Bahnen gelenkt werden.

Die Danziger Flugschriften, die hier besprochen wurden, könnten noch unter weiteren Gesichtspunkten erforscht werden. Aus Platzgründen wurden hier etwa die zeitgenössischen Reiseführer, die den deutschen Diskurs um die Freie Stadt Danzig ebenfalls widerspiegeln, als Interpretationskontext ausgespart. Vielversprechend scheint außerdem eine vergleichende Betrachtung der touristischen Ephemera von damals und heute zu sein. Solch ein diachroner Vergleich, der sich übrigens auch an Flugschriften in deutscher und polnischer Sprache vornehmen ließe, könnte veranschaulichen, inwiefern die Hanse als binationaler Erinnerungsort in touristischen Werbetexten immer noch präsent ist und welche Rolle sie für die deutsche und die polnische Erinnerungsgemeinschaft heute erfüllt.

Quellentexte: Flugschriften und Broschüren mit Signaturen (aus den Sammlungen der PAN Biblioteka Gdańska, Pracownia Dokumentów Życia Społecznego)

Danzig $(4727 / 5)$

Danzig $(4727 / 15)$

Danzig (P5/1933) 
Danzig $(5108 / 17)$

Danzig. Die Königin an der Ostsee (P6/30)

Danzig - die Königin der Ostsee (2652/05)

Danzig und seine Seebäder (P4/1936)

Danzig und seine Seebäder $(5332 / 18)$

Danzig und seine Seebäder (5093/17)

Freie Stadt Danzig (5107/17)

Freie Stadt Danzig (5271/18)

Ostseebad-Zoppot. Das Weltbad an der Ostsee (4703/15)

Zoppot (5237/17)

Zoppot, Freie Stadt Danzig. Das Weltbad an der Ostsee (4675/15)

Was kostet der Aufenthalt in Danzig (4791/16)

\section{Sonstige Quellentexte}

Adressbuch für Danzig und Vororte 1925 (Signatur der PAN Biblioteka Gdańska: III 05543)

Danziger Einwohnerbuch 1937/38 mit allen Vororten und Zoppot (Signatur wie oben)

Danziger Volksstimme: Organ für die werktätige Bevölkerung der Freien Stadt Danzig. Danzig: Fooken, 25.04.1924 (97. Ausgabe)

Der Danziger Vorposten 20.12.1940

\section{Bibliographie}

AndrZejewski, Marek (1998): Dzieje Sopotu w latach 1920-1945 [Geschichte von Zoppot 19201945]. In: ŚLIwIŃski, Błażej (Hg.): Dzieje Sopotu do roku 1945 [Geschichte von Zoppot bis 1945]. Gdańsk: Oficyna Pomorska, 152-184.

Assmann, Aleida (2009): Formen und Wandlungen des kulturellen Gedächtnisses. München: Beck.

Assmann, Jan (1988): Kollektives Gedächtnis und kulturelle Identität. In: Ders. / HöLscher, Tonio (Hg.): Kultur und Gedächtnis. Frankfurt a.M.: Suhrkamp, 9-19.

BelZyT, Leszek C. (2014): Ostkolonisation: Zivilisation aus dem Westen? In: HaHn, Hans Henning / Traba, Robert (Hg.): Deutsch-Polnische Erinnerungsorte. Bd. 2: Geteilt / Gemeinsam. Paderborn: Schöningh, 227-245.

BRAUDEL, Fernand (1977): Geschichte und Sozialwissenschaften. Die longue durée. In: BLOCH, Marc / Braudel, Fernand / Febvre, Lucien: Schrift und Materie der Geschichte. Vorschläge zu einer systematischen Aneignung historischer Prozesse. Frankfurt a.M.: Suhrkamp, 47-85.

Daniluk, Jan (2011a): Gdańskie korporacje akademickie (cz. I) - zarys problematyki, stan badań oraz lata 1904-1921 [Danziger Studentenverbindungen, Teil I: Grundriss der Problematik, Forschungsstand, Zeitraum 1904-1921]. In: Pismo PG 7/2011, 45-49. https://pg.edu.pl/documents/1152961/1183918/calosc.pdf (31.01.2019).

DANILUK, Jan (2011b): Gdańskie korporacje akademickie (cz. II) - lata 1921-1945 oraz okres po 1989 r. [Danziger Studentenverbindungen, Teil II: Zeitraum 1921-1945 sowie die Zeit nach 1989]. In: Pismo $P G$ 8/2011, 50-52. https://pg.edu.pl/documents/1152961/1184068/calosc.pdf(31.01.2019). 
Dollinger, Philippe (1966): Die Hanse. Übers. v. Marga und Hans Krabusch. Stuttgart: Kröner. FIRlej-Buzon, Aneta (2002): Dokumenty życia spotecznego w teorii i praktyce bibliotekarskiej w Polsce [Ephemera in bibliothekarischer Theorie und Praxis in Polen]. Warszawa: Wydawnictwo Stowarzyszenia Bibliotekarzy Polskich.

François, Etienne / Schulze, Hagen (2009): Einleitung. In: Dies. (Hg.): Deutsche Erinnerungsorte Bd. I. München: Beck, 9-24.

FRIEDRICH, Jacek (2010): Propaganda wizualna Wolnego Miasta Gdańska [Zur visuellen Propaganda der Freien Stadt Danzig]. In: Porta Aurea: Rocznik Zaktadu Historii Sztuki Uniwersytetu Gdańskiego 9 (2010), 182-226.

Górny, Maciej / Hahn, Hans Henning / Kończal, Kornelia / Traba, Robert (2012): Zur Einführung. In: HAHN, Hans Henning / TRABA, Robert (Hg.): Deutsch-Polnische Erinnerungsorte. Bd. 3: Parallelen. Paderborn: Schöningh, 11-19.

GruszCZyŃska, Ewa (2012): Dawne polskieprzektady prasowe. Informacja-perswazja - manipulacja [Alte polnische Presse-Übersetzungen. Information - Persuasion - Manipulation]. Warszawa: Oficyna Wydawnicza ASPRA-JR.

GrZEGorCZy KOWA, Renata (1991): Problem funkcji języka i tekstu w świetle teorii aktów mowy [Zu den Funktionen von Sprache und Text aus der Perspektive der Sprechakttheorie]. In: BARTMIŃsKI, Jerzy / Grzegorczy Kowa, Renata (Hg.): Funkcje języka i wypowiedzi (= Jezyk a kultura Bd. 4) [Funktionen von Sprache und Aussage]. Wrocław: Wiedza o Kulturze, 11-28.

HaCKMANN, Jörg (2015): Hanse. Mittelalterliche Wirtschaftsgemeinschaft. In: HaHN, Hans Henning / Traba, Robert (Hg.): Deutsch-Polnische Erinnerungsorte. Bd. 1: Geteilt / Gemeinsam. Paderborn: Schöningh, 83-95.

Loew, Peter Oliver (2011): Danzig. Biographie einer Stadt. München: Beck.

Loew, Peter Oliver (2015): Danzig. Eine Stadt schreibt Nationalgeschichten. In: HaHN, Hans Henning / Traba, Robert (Hg.): Deutsch-Polnische Erinnerungsorte. Bd. 1: Geteilt / Gemeinsam. Paderborn: Schöningh, 123-139.

Lu KAs, Katarzyna (2011): Lokale Identität und kollektives Gedächtnis in der Übersetzung. Am Beispiel polnischer und deutscher Werbetexte im Fremdenverkehr. In: JelitTo-PIECHULIK, Gabriela / KsIĘŻY K, Felicja (Hg.): Germanistische Werkstatt 4. Deutsche Sprache und Literatur im Wandel. Nachwuchswissenschaftler für Prof. Maria Katarzyna Lasatowicz. Opole: Wyd. Uniwersytetu Opolskiego, 73-88.

MACIEJEWSKI, Tadeusz (2017): Ustrój konstytucyjny i sądowy napoleońskiego (1807-1814) i wersalskiego (1920-1939) Wolnego Miasta Gdańska w rozwoju prawno-historyczno-porównawczym [Zur Verfassung und Gerichtsbarkeit der Freien Stadt Danzig (1807-1814 und 1920-1939) aus juristisch-historisch-vergleichender Perspektive]. Gdańsk: Wydawnictwo Uniwersytetu Gdańskiego.

Migoń, Krzysztof (2006): Bibliologia o drukach ulotnych i okolicznościowych [Ephemera und Gelegenheitsdrucke in der Buchwissenschaft]. In: Migoń, Krzysztof / Skalska-Zlat, Marta / ŻBikowsKA-Migoń, Anna (Hg.): Druki ulotne i okolicznościowe - wartości i funkcje. Materiaty międzynarodowej konferencji naukowej, Wojnowice, 8-10 października 2004 [Ephemera und Gelegenheitsdrucke - Werte und Funktionen. Beiträge der internationalen wissenschaftlichen Konferenz in Wojnowice, 8.-10. Oktober 2004]. Wrocław: Wydawnictwo Uniwersytetu Wrocławskiego, 9-19.

Mocarz, Maria (2011): Interkulturowossć w przewodniku turystycznym. Studium o odbiorze inności w przektadzie [Interkulturalität in einem Reiseführer. Studium zur Rezeption von Alterität in der Übersetzung]. Lublin: Wydawnictwo KUL. 
NorA, Pierre (1998): Zwischen Geschichte und Gedächtnis. Aus d. Franz. v. Wolfgang Kaiser. Frankfurt a.M.: Fischer.

OrŁowski, Hubert (2013): Der Namen viele... Stereotype der langen Dauer und Erinnerungsorte. In: Hahn, Hans Henning / Traba, Robert (Hg.): Deutsch-Polnische Erinnerungsorte. Bd. 4: Reflexionen. Paderborn: Schöningh, 107-119.

PAgeL, Karl (1942): Die Hanse. Oldenburg i. O.: Gerhard Stalling Verlag.

ReIss, Katharina (2000): Texttyp und Übersetzen. In: Dies.: Grundfragen der Übersetzungswissenschaft. Wiener Vorlesungen. Wien: WUV, 81-91.

ReSCH, Renate (2006): Translatorische Textkompetenz. Texte im Kulturtransfer. Frankfurt a.M.: Lang.

SAmsonowicz, Henryk (1958): Hanza - wtadczyni mórz [Die Hanse - Herrscherin der Meere]. Warszawa: Książka i Wiedza.

SCHILDHAuer, Johannes (1984): Die Hanse. Geschichte und Kultur. Leipzig: Edition Leipzig.

Schild hauer, Johannes / Fritze, Konrad / Stark, Walter (1974): Die Hanse. Berlin: VEB Deutscher Verlag der Wissenschaften.

Schottenloher, Karl (1922): Flugblatt und Zeitung. Ein Wegweiser durch das gedruckte Tagesschrifttum. Berlin: Richard Carl Schmidt \& Co.

SchüMer, Dirk (2009): Die Hanse. In: François, Etienne / Schulze, Hagen (Hg.): Deutsche Erinnerungsorte Bd. II. München: C.H. Beck, 369-386.

Smykata, Marta (2015): Wenn jemand eine Reise tut... Die kontrastive Textologie am Beispiel der österreichischen und polnischen Tourismuswerbung. Frankfurt a.M.: Lang.

SURYNT, Izabela (2007): Badania postkolonialne a „Drugi Świat”. Niemieckie konstrukcje narodowo-kolonialne XIX wieku [Postkoloniale Forschung und die „Zweite Welt.“ Deutsche national-koloniale Konstruktionen im 19. Jahrhundert]. In: Teksty Drugie 4/2007, 25-46.

WANG, Zhiqiang (2003): Reiseführer und Reiseführerforschung. In: WIERLACHER, Alois / BOGNER, Andrea (Hg.): Handbuch interkulturelle Germanistik. Stuttgart, Weimar: Metzler, 581-587.

\section{Nachschlagewerke}

Birkenmajer, Aleksander et al. (Hg.) (1971): Encyklopedia wiedzy o książce [Enzyklopädie der Buchwissenschaft]. Wrocław, Warszawa, Kraków: Zakład Narodowy im. Ossolińskich (= EWoK). Gedanopedia, https://www.gedanopedia.pl/gdansk/ (31.01.2019).

Lexikon des gesamten Buchwesens, https://referenceworks.brillonline.com/browse/lexikon-des-gesamten-buchwesens-online (31.01.2019).

Schanze, Helmut (Hg.) (2002): Metzler Lexikon Medientheorie Medienwissenschaft. Ansätze - Personen - Grundbegriffe. Stuttgart, Weimar: Metzler (= MLMM).

Abbildungen: Touristische Flugschriften aus der Freien Stadt Danzig, aus den Sammlungen der PAN Biblioteka Gdańska

(c) PAN Biblioteka Gdańska 